\title{
PERCEPÇÃO DA PRESENÇA DE PARADIGMAS DA BIBLIOTECONOMIA E CIÊNCIA DA INFORMAÇÃO EM UMA BIBLIOTECA UNIVERSITÁRIA
}

\author{
Alice de Amorim Borges Vazquez \\ Bibliotecária - BC/UDESC \\ Mestranda de Gestão da Informação - UDESC \\ lika.aliceborges@gmail.com \\ Elaine Rosangela de Oliveira Lucas \\ Doutora em Ciência da informação \\ Professora no Programa de Pós-Graduação em Gestão da Informação (PPGInfo) e do \\ Departamento de Biblioteconomia (DBI). \\ lanilucas@gmail.com
}

\section{Resumo}

\begin{abstract}
Analisa pontos paradigmáticos de uma biblioteca universitária com o objetivo de identificar a presença dos paradigmas da Biblioteconomia e Ciência da Informação e verificar qual deles mais se destaca na presente instituição. Para tanto, esta observação, definiu como objeto de pesquisa a biblioteca central de uma instituição de ensino superior. Inicialmente, são apresentados breves históricos sobre a Biblioteconomia e a Ciência da Informação, além do histórico institucional. Para que fosse possível a pesquisa, levantaram-se dados da instituição quanto a suas características de acervo, empréstimo, consulta, bem como a quantidade de usuários e de colaboradores. Trata-se de uma pesquisa qualitativa, bibliográfica e documental. Por fim, a partir dos paradigmas de Biblioteconomia e de Ciência da Informação, expostos na literatura constatou-se que os principais paradigmas identificados na biblioteca observada estão realmente relacionados com a área da Biblioteconomia, visto ser uma instituição voltada essencialmente ao acervo, suporte e processo técnico.
\end{abstract}

Palavras-chave: Biblioteca Universitária. Paradigmas da Biblioteconomia. Paradigmas da Ciência da Informação.

\section{INTRODUÇÃO}

No pós-guerra, estabeleceu-se o fenômeno da Guerra Fria, um período de conflito entre EUA e URSS, sem confronto direto, no qual os dois países eram competitivos e despendiam esforços para manter suas lideranças num mundo dividido em dois blocos hegemônicos. Por se destacarem, estas superpotências, defendiam cada uma, seus ideais, gerando um conflito de ordem política, militar, tecnológica, econômica, social e ideológica entre os países e suas zonas de influência.

Diante desse acontecimento e perante esse contexto, a produção científica e tecnológica progrediu-se exponencialmente. A informação passou a ser entendida ainda mais como um recurso primordial na produtividade e acelerou a velocidade de produção de novos conhecimentos científicos, principalmente nos meios econômicos e políticos. Esse fato ficou conhecido como "explosão da informação".

Portanto, um dos desafios dos profissionais da área da informação na atualidade é saber como organizar e disseminar as informações relevantes a determinado usuário ao ponto de transformar essa informação em conhecimento. De acordo com Le Coadic (2004, p. 1), "a informação, seja ela escrita, oral ou audiovisual, vende-se bem. [...] cada vez mais e em grande quantidade. $\mathrm{O}$ rápido desenvolvimento do consumo de produtos informais é um fenômeno recente".

É notório que, a partir de um fato ou necessidade, surgem novas áreas para suprir demandas ocasionadas pelo crescimento 
significativo nos problemas oriundos da organização e disseminação do conhecimento. Para Oliveira (2008), é nesse contexto que surge a Ciência da Informação (CI) com forte influência da Biblioteconomia para organizar e disponibilizar o conhecimento cultural, científico e tecnológico produzido. Nesse sentido, pode-se afirmar que a informação é um desafio de ampla discussão na sociedade.

Este artigo torna-se relevante, pois proporciona uma reflexão sobre os paradigmas atuais das principais áreas que estudam o fluxo da informação, como a Biblioteconomia e a CI. Seu objetivo principal é identificar os pontos paradigmáticos observados em uma biblioteca universitária a partir dos paradigmas da Biblioteconomia e da CI apontados pela literatura.

Portanto, após apresentação da Biblioteca universitária, o artigo propõe à mesma reflexão sobre os serviços prestados, além de propor ações de melhoria, possibilitando a biblioteca a auto avaliação da sua gestão e, consequentemente, a quebra e geração de novos paradigmas.

\section{PARADIGMAS DA BIBLIOTECONOMIA E CIÊNCIA DA INFORMAÇÃO NA LITERATURA}

A Biblioteconomia e a Ciência da Informação representam campos científicos orientados por paradigmas diferentes. Os paradigmas são conceitos importantes das comunidades científicas, e, resumidamente, podemos conceituar paradigma como uma visão de mundo adotada em uma determinada época.

Como pressupostos das ciências, os paradigmas são mecanismos usados por cientistas para buscar respostas para os problemas colocados pelas ciências. De acordo com Kuhn (1991), o conceito de paradigma está relacionado à atividade de pesquisa, visando à transformação e à ampliação do conhecimento. $\mathrm{O}$ autor afirma ainda que o paradigma se constitui como uma rede que engloba compromissos, conceitos, teorias, metodologias e instrumentos compartilhados.

$\mathrm{O}$ conceito de paradigma difundido e aceito por Thomas Kuhn traz paradigma como representação de um modelo a ser seguido, um protótipo ou um padrão. "Paradigmas são um conjunto de regras, leis, conceitos e até mesmo métodos utilizados por uma determinada comunidade científica em um determinado tempo" (KUHN apud RUFFO, 20--, p. 2).

Kuhn estabeleceu um conceito-chave de paradigma como "aquilo que os membros de uma comunidade partilham, e, inversamente, uma comunidade científica consiste em homens que partilham um paradigma" (KUHN, 2009, p. 221). Os cientistas que compartilham um mesmo paradigma, na visão de Kuhn (1991), fixam-se nas mesmas regras e padrões na hora da prática científica.

A partir da compreensão e dessa breve explanação do conceito de paradigma, é possível refletir com maior profundidade sobre os paradigmas presentes no contexto da Biblioteconomia e da Ciência da Informação.

\subsection{BIBLIOTECONOMIA E CIÊNCIA DA INFORMAÇÃO}

Considerada hoje como uma das mais antigas disciplinas que se ocupa do acesso à informação e de sua transmissão para os povos futuros, a Biblioteconomia, como área do conhecimento, tem seu foco inicial, segundo Le Coadic (2004, p. 12-13),

a) nos acervos de livros (formação, desenvolvimento, classificação, catalogação, conservação); b) na própria biblioteca como instituição organizada (regulamento, pessoal, contabilidade, instalações, infraestrutura) e c) nos leitores/usuários (direitos e deveres, acesso ao acervo, empréstimos).

Para Le Coadic (2004), a Biblioteconomia não é uma ciência, é uma prática de organização, ou seja, a arte de organizar bibliotecas. Mas, como organizar as informações que já não estão mais disponíveis fisicamente? Esta é uma dúvida que persiste no âmbito de estudo e pesquisa.

As bibliotecas tradicionais foram sucedidas por organizações que reúnem os mais diversificados tipos de acervos, em qualquer suporte e de qualquer origem, ocasionando o surgimento de um novo ambiente informacional. Barbosa (2000) aborda que na atualidade, a Biblioteconomia lida com a informação em diferentes contextos e não apenas com livros no 
ambiente da biblioteca. Na visão da autora, a Biblioteconomia não conseguiu acompanhar o avanço das tecnologias da maneira esperada pela sociedade, abrindo caminho para o surgimento de uma nova área, a Ciência da Informação. "O termo biblioteconomia remete a uma imagem inadequada de seu objeto de estudo e de sua relação com o mercado de trabalho" (BARBOSA, 2000, p. 88).

Assim, entende-se que, com o advento das tecnologias, mudanças no perfil dos profissionais da informação e nas organizações das bibliotecas são necessárias, assim como a sugestão de alteração no termo usuário.

Os usuários da biblioteca tornaram-se interagentes, termo utilizado por Corrêa (2014, p. 24), para referir-se "tanto aos sujeitos utilizadores dos serviços e produtos oferecidos pelas UI, quanto aos sujeitos que, independente de frequentarem essas unidades, acessam e usam a informação em seus diferentes suportes e nos mais diferentes canais".

Para Corrêa, o termo "usuário" deveria ser utilizado quando nos referimos àquele que busca informação no ambiente da biblioteca, ou seja, aquele que usa a biblioteca, seus recursos de informação. "Aquele que faz uso da informação para melhorar seus trabalhos, pesquisas e conhecimentos" (CORTEZ, 1987, p. 200 apud CORRÊA, 2014, p. 27). A autora propõe em seus estudos a substituição do termo "usuário" pelo termo "interagente", por entender que, acompanhando as mudanças tecnológicas nos tempos atuais, os usuários necessitam das informações atuais e em tempo real. $\mathrm{O}$ esperado é que a solução do problema do interagente seja oferecida no mesmo momento em que ele interage com a Unidade de Informação.

Oliveira (2008) aponta que o paradigma da Biblioteconomia tem como ponto focal a biblioteca em si mesma e, portanto, como uma organização social, com material organizacional e características intelectuais que servem como justificador de sua função social. É importante explicitar que o autor justifica isso por considerar a biblioteca o "fio condutor" entre os indivíduos e o conhecimento que eles buscam (OLIVEIRA, 2008).
Refletindo, podemos compreender que, para atender às solicitações dos interagentes de forma eficaz, é necessário que o bibliotecário se comunique adequadamente com o interagente que busca pela informação e entenda do que esse indivíduo necessita naquele momento. Para que as atividades do serviço de referência transcorram de forma correta, são desenvolvidas atividades técnicas de aquisição, organização, tratamento e disseminação de documentos e informação.

Desta forma, encontram-se na literatura, novos conceitos, substituindo assim, a forma de gerenciamento das bibliotecas, antes tradicionais, e agora, em sua maioria, híbridas. De acordo com Barbosa (2000, p. 81), "como consequência dessa explosão informacional, pessoas e organizações enfrentam constantes desafios relacionados ao gerenciamento desse enorme volume de informação".

A Ciência da Informação (CI) nasceu para enfrentar esses problemas gerados pela "explosão da informação". Cada vez mais, os usuários e cientistas em geral buscam informações com rapidez e coerentes às suas necessidades, pois não há fronteira que detenha a informação. As sociedades testemunham nos últimos anos um aumento representativo no acervo do conhecimento da humanidade, revelando-se em bibliotecas tradicionais e virtuais milhares de documentos que podem estar de acordo com a necessidade do usuário. Porém, achar a informação mais relevante àquele momento da busca não é uma tarefa fácil. Exige conhecimento da parte do usuário e do bibliotecário de referência que o auxiliará.

Precisar o surgimento de uma dada disciplina científica é difícil, pois toda ciência é uma atividade social determinada pelas condições históricas e socioeconômicas. Acredita-se ser necessário haver mudanças culturais, econômicas e tecnológicas que provoquem uma mudança epistemológica. "As atividades de pesquisa nunca tiveram nem o vigor nem a extensão que têm hoje em dia." (LE COADIC, 2004, p. 26). O autor afirma ainda que a CI foca a sua preocupação em esclarecer um problema social concreto, o da informação, além de ser voltada para o ser social que procura informação.

Para Le Coadic (2004), com o passar dos acontecimentos, percebeu-se que a sociedade 
da informação precisava de uma ciência que estudasse as propriedades da informação e os processos de sua construção, comunicação e uso. Para Araújo (2009, p. 200), esses "processos são normalmente entendidos como processos técnicos, aplicados, de intervenção".

De acordo com Borko,

Ciência da Informação é a disciplina que investiga as propriedades e o comportamento informacional, as forças que governam os fluxos de informação, e os significados do processamento da informação, visando à acessibilidade e a usabilidade ótima. (BORKO, 1968, p. 1).

"O termo CI teria sido cunhado na década de 1960 a partir de estudos e reflexões empreendidos em torno da produção, processamento e uso da informação no âmbito humano" (LOUREIRO, 1999, p. 65). Na mesma época, surgiram os primeiros conceitos da área. Em geral, eles são semelhantes, elucidando a CI como uma ciência voltada para o estudo da produção, organização, armazenamento, disseminação e uso da informação (ARAÚJO, 2009).

Como visto anteriormente, a Ciência da Informação (CI) tem por objeto de estudo a informação e, por objetivo, solucionar problemas oriundos desta. Considerada uma ciência emergente, a Ciência da Informação enfrenta novos desafios impostos pelo processo de globalização, pela sociedade da informação e pelas novas tecnologias. Desde a sua criação, enfrenta uma crise de identidade, e suas fronteiras com outras disciplinas não estão claramente delimitadas.

Existe uma vasta literatura a respeito da fundamentação que sustenta a Ciência da Informação e quanto à sua origem.

Explorando a literatura da área, parece não existir dúvida entre os autores de que a CI é um campo recente e que surgiu da demanda social pela otimização dos processos de coleta, armazenamento, recuperação e disseminação da informação científica e tecnológica, cuja produção apresentava um crescimento exponencial ao final da década de 50 - a chamada 'crise da informação'. (CARVALHO, 1999, p. 51).
A Ciência da Informação possui as raízes embrionárias no período histórico das grandes guerras mundiais, no bojo da revolução científica e técnica do pós-guerra, mas é na década de 60 que essa nova disciplina firma seus conceitos e definições. Portanto, foi após a Segunda-Guerra Mundial e a Guerra Fria que o crescimento da informação foi significativo, causando problemas de organização e de disseminação do conhecimento registrado.

Consensualmente, os pesquisadores da área admitem que sua origem como disciplina e atividade profissional teve como marco o incremento científico ocorrido após desfecho da segunda guerra mundial, que gerou 0 fenômeno da explosão da informação, a necessidade de controle bibliográfico, o surgimento das indústrias e dos serviços de informação.

Um dos conceitos mais consideráveis no meio científico é o de Taylor (1966 apud CARVALHO, 1999, p. 51): "Ciência da informação é a ciência que investiga as propriedades e o comportamento da informação, as forças que governam o fluxo da informação, e os meios de processamento da informação para um acesso e uso ótimos".

Considerada uma ciência emergente, a CI enfrenta novos desafios impostos pelo processo de globalização e da sociedade da informação, bem como pela interferência das novas tecnologias, o que coloca no centro de todas as questões os problemas relacionados à informação que, em tese e na prática, têm sido seu objeto de estudo. "A consolidação da ciência da informação no Brasil dá um importante passo com a criação, em 1980, da ANCIB - Associação Nacional de Pesquisa e Pós-Graduação em Ciência da Informação \& Biblioteconomia". (BARBOSA, 2000, p. 85).

$O$ conceito de informação tem um importante papel na sociedade contemporânea. Contudo, existe hoje um amplo debate filosófico quanto ao conceito de informação. A dúvida é se o conceito deveria remeter ao processo de conhecimento. Capurro (2007) explica que, atualmente, quase toda disciplina científica usa o conceito de informação dentro de seu próprio contexto e com relação a fenômenos específicos. Portanto, é nítido que o uso da informação é um grande desafio para a sociedade, e a CI surge com o intuito de organizar e 
disponibilizar o conhecimento cultural, científico e tecnológico (OLIVEIRA, 2008 apud VIEIRA, 2015).

"O tipo de atividade realizada pela ciência é a produção de conhecimento e o desenvolvimento de teorias científicas" (CAPURRO, 2007, p. 5). De acordo com Saracevic (1996, p. 60),

[...] nas últimas quatro décadas a CI apresentou contribuições que influenciaram o modo como a informação é manipulada na sociedade e pela tecnologia e também permitiu melhor compreensão para um rol de problemas, processos e estruturas associados ao conhecimento, à informação e ao comportamento humano frente à informação.

Saracevic (1996) identificou também três características da Ciência da Informação: sua interdisciplinaridade, sua vinculação com a tecnologia e sua participação ativa na era da informação. $\mathrm{O}$ autor ainda constata que a área tem mantido vínculos através dos tempos mais acentuadamente com a Biblioteconomia, Ciência da Computação, Ciência Cognitiva e Comunicação. Sem dúvida, dentre elas, a interdisciplinaridade tem maior destaque.

Para Le Coadic (2004), “a interdisciplinaridade traduz-se por uma colaboração entre diversas disciplinas, de modo que haja um enriquecimento mútuo". Dentre essas disciplinas, merecem destaque a Linguística, a Sociologia, a Psicologia e a Política.

Borko (1968) salienta que a Ciência da Informação é a responsável por investigar as propriedades e o comportamento da informação, o uso e a transmissão da informação e o processamento da informação, visando a uma armazenagem e recuperação que sejam ideais à UI. "A CI está preocupada com o corpo de conhecimentos relacionados à origem, coleção, organização, armazenamento, recuperação, interpretação, transmissão, transformação, visando à acessibilidade e a usabilidade ótima" (BORKO, 1968, p. 2).

"A CI tem como meta fornecer um corpus teórico sobre informação que propiciará a melhoria de várias instituições e procedimentos dedicados à acumulação $\mathrm{e}$ transmissão do conhecimento". (BORKO, 1968, p. 2). Saracevic (1996) reforça o pensamento de Borko, alertando que a CI desenvolveu um corpo organizado de conhecimentos e competências profissionais ligados às questões informacionais.

Portanto, nesses últimos tempos, o pesquisador em $\mathrm{CI}$ tem um amplo campo para desenvolver suas pesquisas, reforçado diariamente com a influência dos avanços tecnológicos. Portanto, é nítida a contribuição da CI nas pesquisas dos cursos de pósgraduação, para os pesquisadores, e uma excelente área para investir recursos educacionais.

Por conseguinte, pode-se dizer que a ciência da informação é uma área do conhecimento reconhecida nacional e internacionalmente por meio de cursos, sociedades científicas, periódicos e outras formas de institucionalização. No Brasil, a denominação foi introduzida há quase três décadas, vindo, desde então, se consolidando de forma indiscutível (BARBOSA, 2000, p. $85)$.

Autores como Silva (2012) e Oliveira (2008) consideram ainda que a CI teve influências marcantes de duas outras disciplinas, que contribuíram para seu desenvolvimento: a Documentação e a Recuperação da Informação.

Para Silva (2012) a Recuperação de Informação e a Ciência da Informação caminharam lado a lado desde seu surgimento. "A Recuperação de Informação apresenta um contributo para a Ciência da Informação que se configura em uma condição pertinente para a área até os dias de hoje: procedimentos de representação da informação para uma busca eficiente e eficaz em sistemas" (SILVA, 2012, p. 22).

\section{PROCEDIMENTOS METODOLÓGICOS}

Quanto aos fins, essa pesquisa considerase descritiva, pois, por meio da observação de uma biblioteca universitária, foram levantados os pontos paradigmáticos a partir dos paradigmas da Biblioteconomia e da Ciência da Informação expostos pela literatura.

Quanto aos meios, a pesquisa foi bibliográfica (baseada na literatura revista), documental (pesquisa nos documentos internos da instituição para levantamento de 
informações e dos dados estatísticos), com observação não-estruturada centrada em uma unidade de estudo.

Ventura (2007, p. 1) ressalta que toda pesquisa científica necessita definir seu objeto de estudo e, a partir daí, construir um processo de investigação, delimitando o universo que será estudado. O objetivo da observação não-estruturada, individual e ocasional é que seja um instrumento de investigação, ou seja, uma modalidade de pesquisa que pode ser aplicada em diversas áreas do conhecimento. Portanto, é a técnica mais adequada para este artigo.

Os dados coletados, para a pesquisa foram extraídos de fontes primárias, diretamente no Banco de Dados Pergamum da Biblioteca Universitária, observados e analisados sem uso de gráficos. Segundo descriminação no site da Rede Pergamum, "o sistema [...] contempla as principais funções de uma biblioteca, funcionando de forma integrada, com o objetivo de facilitar a gestão dos centros de informação, melhorando a rotina diária com os seus usuários" (PERGAMUM, 2016).

O levantamento dos dados realizou-se em maio de 2016. Primeiramente foram coletados os dados do ano de 2015 buscando levantar os dados anuais da instituição (01 jan. 2015 a 31 dez. 2015). Logo após, de forma a reforçar a análise, foram coletados os dados de 2016 (01 jan. 2016 a 19 maio 2016).

$O$ instrumento de coleta utilizado foi a observação direta realizada in loco na biblioteca observada, em diversas situações. Não houve interação com o gestor da biblioteca, apenas a atividade de observação e análise da própria pesquisa.

A partir da exposição dos dados e de sua análise, foi possível levantar os paradigmas apresentados na literatura, bem como quais deles estão presentes na Biblioteca observada, e sugerir propostas de ações de melhorias.

\section{BIBLIOTECA OBSERVADA E SEUS PONTOS PARADIGMÁTICOS}

Neste tópico, serão apresentadas as principais características e dados estatísticos da Biblioteca Universitária observada, além da análise dos paradigmas de Biblioteconomia e de Ciência da Informação com base na literatura.

\subsection{CARACTERÍSTICAS DA BIBLIOTECA OBSERVADA}

A Biblioteca Universitária observada integra uma Rede de Bibliotecas de uma Instituição de Ensino Superior Pública, formada por nove bibliotecas. Todas estas bibliotecas prestam serviços de gestão, assistência ao interagente, tratamento técnico da coleção e demais serviços de informação. Cada biblioteca é gerida por um coordenador de apoio. Há ainda um coordenador geral para a Rede de Bibliotecas.

Inicialmente a coleta de dados envolveu a Rede de Bibliotecas com o objetivo de elencar a constituição dessa instituição. Logo em seguida, foram coletados os dados específicos da Biblioteca Universitária Central.

A Biblioteca Central (BC) situa-se na mesma estrutura da sede da instituição, desde 2007. Construída em uma área de $1.440 \mathrm{~m}^{2}$, conta com $431 \mathrm{~m}^{2}$ de área de acervo e $350 \mathrm{~m}^{2}$ de área destinada aos usuários (dados retirados de relatório). Atualmente conta com oito bibliotecárias, além de três servidores de nível médio.

A BC conta com seis objetivos: a) fornecer suporte informacional aos programas de ensino, pesquisa e extensão para a Instituição; b) incentivar a implantação de serviços bibliotecários nas unidades; c) promover a melhoria do funcionamento das bibliotecas, para que atuem como centros de ação cultural e educacional permanentes; d) desenvolver atividades de treinamento e qualificação de recursos humanos, para o funcionamento de todas as bibliotecas; e) assessorar tecnicamente as bibliotecas e coordenadorias, bem como definir diretrizes e normas de funcionamento e orientadoras de suas atividades; f)firmar convênios com entidades culturais, visando à promoção dos serviços, produtos e atividades das bibliotecas.

Inicialmente esta biblioteca universitária funcionou sob a forma de centralização parcial; posteriormente descentralizou as funções técnicas, passando para as setoriais todas as funções. Em 2001, adotou o sistema de trabalho cooperativo, por meio da formação de grupos de trabalho, em que as diretrizes e normas passaram a ser definidas em conjunto com todas as bibliotecas através 
dos Grupos de Trabalho. A informatização de seus serviços começou nessa época com a adoção do Sistema Pergamum, padronizando todas as atividades das bibliotecas.

O horário de funcionamento é das $7 \mathrm{~h} 30 \mathrm{~min}$ às $21 \mathrm{~h} 45 \mathrm{~min}$; a biblioteca conta com uma bibliotecária no horário matutino e as demais no horário vespertino. Seu públicoalvo é a comunidade universitária: alunos, professores, servidores e comunidade em geral. Em torno de 45.571usuários possuem cadastro na Rede de Bibliotecas, porém deste total, apenas - 31.139 estão com o cadastro ativo. Desta forma, pode-se analisar que é esse o público que a biblioteca visa atender. No último ano (2015), foram realizados 119.136 empréstimos na Rede de Bibliotecas. Já em 2016, até o período analisado (abril) o número de empréstimos foi de -35.880 . O acervo adquirido foi de 6.180 títulos no ano de 2015 e 1629 títulos de janeiro a abril de 2016.

\subsection{DADOS ESTATÍSTICOS DA BIBLIOTECA OBSERVADA}

Buscou-se apresentar os principais dados estatísticos da Biblioteca observada, reforçando o contexto dessa pesquisa com o intuito de promover um melhor aproveitamento dos resultados obtidos. Os dados levantados serão analisados logo em seguida: número de obras no acervo, empréstimos, consulta ao acervo e número de interagentes cadastrados na Biblioteca Central. Com base nesses dados, foi possível inferir que estes refletem os paradigmas da Biblioteconomia como os mais relevantes.

O acervo da instituição é formado por livros, folhetos, catálogos, artigos, monografias, teses, monografias de pósgraduação, dissertações, música, periódicos, DVD, monografias digitais (incluindo as de pós-graduação), peças de teatro, gravações de vídeo, mapas, CD-ROMs e gravações de som.

No quadro 1, estão expostas as características de acervo total da Rede de Bibliotecas, enquanto no quadro 2, estão expostos os dados do acervo total, apenas da Biblioteca

Central.

Quadro 1 - Característica de acervo total da Rede de Bibliotecas - em números

\begin{tabular}{|c|c|}
\hline \multicolumn{2}{|c|}{$\begin{array}{l}\text { ESTATÍSTICA DE ACERVOS - REDE DE } \\
\text { BIBLIOTECAS }\end{array}$} \\
\hline \multicolumn{2}{|l|}{ Período: 01/01/2015 à 30/04/2015 } \\
\hline Total de acervos & 1731 \\
\hline Total de exemplares & 2419 \\
\hline \multicolumn{2}{|l|}{ Período: 01/05/2015 à 31/08/2015 } \\
\hline Total de acervos & 2203 \\
\hline Total de exemplares & 4194 \\
\hline \multicolumn{2}{|l|}{ Período: 01/09/2015 à 31/12/2015 } \\
\hline Total de acervos & 2246 \\
\hline Total de exemplares & 5036 \\
\hline \multicolumn{2}{|l|}{ Período: 01/01/2016 à 30/04/2016 } \\
\hline Total de acervos & 1629 \\
\hline Total de exemplares & 3232 \\
\hline
\end{tabular}

Segundo Almeida (2005, p. 42), “este item deve conter dados totais das coleções dos vários tipos de materiais encontrados na biblioteca".

Quadro 2 - Característica de acervo total da Biblioteca Central - em números

\begin{tabular}{|r|r|}
\hline \multicolumn{2}{|c|}{ ESTATISTICA DE ACERVOS } \\
BIBLIOTECA CENTRAL \\
\hline Período: 01/01/2015 à 30/04/2015 \\
\hline Total de acervos & 469 \\
\hline Total de exemplares & 386 \\
\hline Período: 01/05/2015 à 31/08/2015 \\
\hline
\end{tabular}




\begin{tabular}{|r|r|}
\hline Total de acervos & 978 \\
\hline Total de exemplares & $\mathbf{1 0 0}$ \\
& 1 \\
\hline Período: 01/09/2015 à 31/12/2015 & 972 \\
\hline Total de acervos & $\mathbf{1 5 3}$ \\
\hline Total de exemplares & 3 \\
\hline Período: 01/01/2016 á 30/04/2016 & \\
\hline Total de acervos & $\mathbf{7 0 2}$ \\
\hline Total de exemplares & $\mathbf{6 9 7}$ \\
\hline Fonte: Dados da Pesquisa (2016). \\
\hline
\end{tabular}

Conforme será apresentado no quadro 3, pode-se observar a quantidade de empréstimos realizados em toda a Rede de Bibliotecas da instituição, durante o ano de 2015 e até final de abril de 2016 (em períodos pré-selecionados). A biblioteca A encerrou suas atividades no ano de 2015. A biblioteca $\mathrm{K}$ e L estão localizadas no mesmo local e atendem apenas dois cursos da universidade.

Quadro 3 - Volume de empréstimo por Unidade da Rede de Bibliotecas

\begin{tabular}{|c|c|c|c|c|}
\hline \multicolumn{5}{|c|}{ ESTATÍSTICA DE CIRCULAÇÃ̃O DE MATERIAIS - REDE DE BIBLIOTECAS } \\
\hline \multirow{2}{*}{$\begin{array}{l}\text { UNIDADES DA REDE DE } \\
\text { BIBLIOTECAS }\end{array}$} & \multicolumn{4}{|c|}{ PERÍODOS } \\
\hline & $\begin{array}{c}01 / 01 / 2015 \\
\grave{a ̀} \\
30 / 04 / 2015\end{array}$ & $\begin{array}{c}01 / 05 / 2015 \\
\grave{a} \\
31 / 08 / 2015\end{array}$ & $\begin{array}{c}01 / 09 / 2015 \\
\grave{a ̀} \\
31 / 12 / 2015\end{array}$ & $\begin{array}{c}01 / 01 / 2016 \\
\grave{a} \\
30 / 04 / 2016\end{array}$ \\
\hline $\mathrm{BC}$ & 12186 & 14397 & 12944 & 11792 \\
\hline Biblioteca A & 07 & 00 & 00 & 00 \\
\hline Biblioteca B & 00 & 00 & 00 & 02 \\
\hline Biblioteca $\mathrm{C}$ & 729 & 769 & 339 & 425 \\
\hline Biblioteca D & 2144 & 3144 & 2714 & 3060 \\
\hline Biblioteca E & 1925 & 1806 & 1558 & 1617 \\
\hline Biblioteca F & 6085 & 6693 & 6623 & 6363 \\
\hline Biblioteca G & 3577 & 3737 & 3870 & 3303 \\
\hline Biblioteca H & 4524 & 5012 & 4951 & 4643 \\
\hline Biblioteca I & 3105 & 3012 & 2782 & 2260 \\
\hline Biblioteca J & 1038 & 1095 & 1348 & 996 \\
\hline Biblioteca K & 1630 & 1640 & 1370 & 828 \\
\hline Biblioteca L & 823 & 746 & 813 & 591 \\
\hline Total Geral & 37773 & 42051 & 39312 & 35880 \\
\hline
\end{tabular}

Fonte: Dados da pesquisa (2016).

Já no quadro 4, constam apenas os dados de empréstimo da Biblioteca Central (disposto da mesma forma que o anterior). Entende-se por empréstimo a circulação externa de material (ALMEIDA, 2005, p. 48).

Esta Rede de Bibliotecas adota a Classificação Decimal de Dewey na classificação do seu acervo. Percebe-se que a maior procura por empréstimos está no acervo de classe 300, ou seja, das Ciências Sociais, portanto este é um item a ser aprofundado na hora de novas aquisições, buscando manter o acervo da instituição sempre atualizado.

Quadro 4 - Volume de empréstimo na Biblioteca Central pela Classificação ESTATÍSTICA DE CIRCULAÇÃO DE MATERIAIS BIBLIOTECA CENTRAL

\begin{tabular}{|c|c|c|c|c|}
\hline \multicolumn{5}{|c|}{ ESTATISTICA DE CIRCULAÇÃO DE MATERIAIS } \\
\hline \multirow{5}{*}{ BIBLIOTECA CENTRAL } \\
\hline \multirow{3}{*}{ Classe CDD } & $\mathbf{0 1 / 0 1 / 2 0 1 5}$ & $\mathbf{0 1 / 0 5 / 2 0 1 5}$ & $\mathbf{0 1 / 0 9 / 2 0 1 5}$ & $\mathbf{0 1 / 0 1 / 2 0 1 6}$ \\
& $\grave{a}$ & à & à & à \\
\hline
\end{tabular}




\begin{tabular}{|c|c|c|c|c|}
\hline & $\mathbf{3 0 / 0 4 / 2 0 1 5}$ & $\mathbf{3 1 / 0 8 / 2 0 1 5}$ & $\mathbf{3 1} / \mathbf{1 2} / \mathbf{2 0 1 5}$ & $\mathbf{3 0 / 0 4 / 2 0 1 6}$ \\
\hline 000 & 649 & 922 & 795 & 720 \\
\hline 100 & 687 & 838 & 968 & 660 \\
\hline 200 & 57 & 100 & 139 & 65 \\
\hline $\mathbf{3 0 0}$ & $\mathbf{4 0 9 1}$ & $\mathbf{4 8 9 2}$ & $\mathbf{4 3 3 0}$ & $\mathbf{4 0 0 1}$ \\
\hline 500 & 60 & 156 & 133 & 106 \\
\hline 600 & 382 & 595 & 446 & 564 \\
\hline 700 & 2166 & 2298 & 1934 & 1958 \\
\hline 800 & 2552 & 2738 & 2444 & 2373 \\
\hline 900 & 881 & 1056 & 1068 & 944 \\
\hline Total Geral & 889 & 1070 & 911 & 655 \\
\hline
\end{tabular}

Fonte: Dados da pesquisa (2016).

O quadro 5 demonstra como foi a distribuição do empréstimo por tipo de material nos mesmos períodos.

Quadro 5 - Distribuição de empréstimo na Biblioteca Central pelo tipo de material ESTATÍSTICA DE CIRCULAÇÃO DE MATERIAIS - BIBLIOTECA CENTRAL PERÍODOS

\begin{tabular}{|c|c|c|c|c|}
\hline TIPO DE MATERIAL & $\mathbf{0 1 / 0 1 / 2 0 1 5}$ & $\mathbf{0 1 / 0 5 / 2 0 1 5}$ & $\mathbf{0 1 / 0 9 / 2 0 1 5}$ & $\mathbf{0 1 / 0 1 / 2 0 1 6}$ \\
& $\begin{array}{c}\text { à } \\
\mathbf{3 0 / 0 4 / 2 0 1 5}\end{array}$ & $\begin{array}{c}\text { à } \\
\mathbf{3 1 / 0 8 / 2 0 1 5}\end{array}$ & $\begin{array}{c}\mathbf{3} \\
\mathbf{3 1 / 1 2} / \mathbf{2 0 1 5}\end{array}$ & $\mathbf{3 0 / 0 4 / 2 0 1 6}$ \\
\hline Livros & 30639 & 46295 & 37974 & 30269 \\
\hline Dissertações & 07 & 14 & 99 & 55 \\
\hline Folhetos & 00 & 04 & 02 & 00 \\
\hline Monografias & 03 & 04 & 01 & 01 \\
\hline Monografia de Pós- & 00 & 03 & 01 & 00 \\
\hline graduação & & & & \\
\hline Teses & 03 & 04 & 00 & 00 \\
\hline Música & 99 & 43 & 59 & 48 \\
\hline Periódicos & 05 & 06 & 08 & 02 \\
\hline DVD & 127 & 156 & 120 & 59 \\
\hline Peças de teatro & 01 & 01 & 00 & 01 \\
\hline Gravação de vídeo & 01 & 08 & 07 & 01 \\
\hline CD-ROMs & 07 & 05 & 03 & 00 \\
\hline Mapas & 00 & 04 & 01 & 00 \\
\hline Gravação de som & 01 & 02 & 02 & 02 \\
\hline Total Geral & $\mathbf{3 0 8 9 8}$ & $\mathbf{4 6 5 4 9}$ & $\mathbf{3 8 2 7 7}$ & $\mathbf{3 0 4 3 8}$ \\
\hline
\end{tabular}

Fonte: Dados da pesquisa (2016).

No quadro 6 estão dispostos os dados de consulta interna no acervo da Rede de Bibliotecas. Ao consultar o acervo da biblioteca, nem sempre o usuário realizará o empréstimo. Poderá realizar apenas o estudo no espaço físico da biblioteca e nesse caso, a recomendação da biblioteca é que o usuário deixe o material na mesa após consulta interna. Funcionários bolsistas fazem o recolhimento desse material nas mesas, e passam em um leitor que contabilizam esses dados.

"Entende-se por consulta o uso do material no recinto da biblioteca" (ALMEIDA, 2005, p. 48). 
Quadro 6 - Consulta ao acervo por períodos - Rede de Bibliotecas

\begin{tabular}{|c|c|}
\hline \multicolumn{2}{|c|}{$\begin{array}{l}\text { ESTATÍSTICA DE CONSULTA INTERNA } \\
\text { NO ACERVO - BIBLIOTECA CENTRAL }\end{array}$} \\
\hline \multicolumn{2}{|c|}{ Período: 01/01/2015 à 30/04/2015 } \\
\hline Total & 13848 \\
\hline \multicolumn{2}{|l|}{ Período: 01/05/2015 à 31/08/2015 } \\
\hline Total & 19900 \\
\hline \multicolumn{2}{|l|}{ Período: 01/09/2015 à 31/12/2015 } \\
\hline Total & 18583 \\
\hline \multicolumn{2}{|l|}{ Período: 01/01/2016 à 30/04/2016 } \\
\hline Total & 12480 \\
\hline
\end{tabular}

Fonte: Dados da Pesquisa (2016).

Abaixo, quadro 7, temos a consulta interna no acervo da Biblioteca Central. Da mesma forma que acontece na Rede é realizado o levantamento específico na Central.

Quadro 7 - Consulta ao acervo por períodos - Biblioteca Central

\begin{tabular}{|c|c|}
\hline \multicolumn{2}{|c|}{$\begin{array}{l}\text { ESTATÍSTICA DE CONSULTA INTERNA NO } \\
\text { ACERVO - BIBLIOTECA CENTRAL }\end{array}$} \\
\hline \multicolumn{2}{|c|}{ Período: 01/01/2015 à 30/04/2015 } \\
\hline Total & 3535 \\
\hline \multicolumn{2}{|l|}{ Período: 01/05/2015 à 31/08/2015 } \\
\hline Total & 6078 \\
\hline \multicolumn{2}{|l|}{ Período: 01/09/2015 à 31/12/2015 } \\
\hline \multirow{2}{*}{\multicolumn{2}{|c|}{ Período: 01/01/2016 à 30/04/2016 }} \\
\hline & \\
\hline Total & 2926 \\
\hline
\end{tabular}

Fonte: Dados da Pesquisa (2016).

O quadro 8 explana a quantidade dos interagentes cadastrados na Rede de Bibliotecas podendo indicar se a utilização da Biblioteca é relevante institucionalmente. A quantidade de usuários ativos é composta por aqueles que podem realizar empréstimos. $\mathrm{Na}$ quantidade geral de usuários apresenta-se todos que já realizaram cadastro na biblioteca, ativos e inativos.

Quadro 8 - Usuários cadastrados na Rede de Bibliotecas

\begin{tabular}{|c|c|}
\hline \multicolumn{2}{|c|}{ ESTATÍSTICA DE USUÁRIO } \\
\hline PERÍODO: 01/01/1980 à 30/04/2016 \\
Quantidade de usuários ativos & $\mathbf{3 1 1 3 9}$ \\
\hline Quantidade geral de usuários & $\mathbf{4 5 5 7 1}$ \\
\hline
\end{tabular}

Fonte: Dados da Pesquisa (2016)

O quadro 9 apresenta a quantidade de profissionais que trabalham na Rede de bibliotecas. "Este item deve fornecer dados sobre o pessoal em exercício no período" (ALMEIDA, 2005, p. 43).

Quadro 9 - Profissionais da Rede de Bibliotecas (continua)

\begin{tabular}{|c|c|c|c|}
\hline \multicolumn{4}{|c|}{ PROFISSIONAIS DA REDE DE } \\
\hline UNIDADES DA REDE & Bibliotecários & Auxiliares & Bolsistas \\
\hline BC & $\mathbf{8}$ & $\mathbf{4}$ & $\mathbf{9}$ \\
\hline Biblioteca A & $\mathbf{0}$ & $\mathbf{0}$ & $\mathbf{0}$ \\
\hline Biblioteca B & $\mathbf{0}$ & $\mathbf{0}$ & $\mathbf{0}$ \\
\hline
\end{tabular}




\begin{tabular}{|c|c|c|c|}
\hline Biblioteca C & $\mathbf{1}$ & $\mathbf{0}$ & $\mathbf{1}$ \\
\hline Biblioteca D & $\mathbf{1}$ & $\mathbf{1}$ & $\mathbf{3}$ \\
\hline Biblioteca E & $\mathbf{1}$ & $\mathbf{1}$ & $\mathbf{2}$ \\
\hline Biblioteca F & $\mathbf{2}$ & $\mathbf{6}$ & $\mathbf{6}$ \\
\hline Biblioteca G & $\mathbf{1}$ & $\mathbf{4}$ & $\mathbf{5}$ \\
\hline Biblioteca H & $\mathbf{3}$ & $\mathbf{1}$ & $\mathbf{5}$ \\
\hline Biblioteca I & $\mathbf{1}$ & $\mathbf{0}$ & $\mathbf{4}$ \\
\hline Biblioteca J & $\mathbf{1}$ & $\mathbf{2}$ & $\mathbf{0}$ \\
\hline Biblioteca K & $\mathbf{0}$ & $\mathbf{0}$ & $\mathbf{0}$ \\
\hline Biblioteca L & $\mathbf{1}$ & $\mathbf{1}$ & $\mathbf{3}$ \\
\hline Total Geral & $\mathbf{2 0}$ & $\mathbf{2 0}$ & $\mathbf{3 8}$ \\
\hline
\end{tabular}

Fonte: Dados da pesquisa (2016).

O quadro de pessoal (11) serve para especificar a quantidade de pessoas nas diferentes categoriais. Salienta-se aqui a disposição dos bibliotecários: Serviço de Referência (1), Setor de Apoio ao Usuário (1), Setor de Periódicos e Multimeios (1), Setor de Processamento Técnico (3), Coordenação BU (1), Coordenação local (1). Os auxiliares trabalham em funções técnicas de biblioteca, tais como atendimento ao público e inserção de etiquetas nos materiais, enquanto os bolsistas contratados são estudantes de diversos cursos interessados em aprender um pouco do ambiente informacional de uma biblioteca.

\subsection{PONTOS PARADIGMÁTICOS E OPORTUNIDADES DE MELHORIAS DA BIBLIOTECA OBSERVADA}

Após levantamento dos pontos paradigmáticos da Biblioteconomia e Ciência da Informação, apresentados pela literatura da área, buscou-se identificar os aspectos relevantes observados na biblioteca universitária pesquisada apresentando breve diagnóstico e sugestão de melhoria nos pontos desfavoráveis a boa gestão da biblioteca e que estão elencados abaixo:

a) Foco no documento/suporte físico. Considerar o documento mais importante (Biblioteconomia).

Justificativa: Percebeu-se que a preocupação maior está focada nos documentos e na sua forma de armazenamento. Poucas vezes a biblioteca observou o conteúdo desses documentos.

Sugestão: Focar na informação que esse documento traz para a biblioteca, analisando suas possíveis utilizações na instituição, podendo ser redistribuído para outra
Biblioteca da rede, mais adequada, gerando assim uma melhor utilização.

b) Foco nos processos internos/organização da biblioteca/equipamentos. Pouca preocupação com o usuário (Biblioteconomia).

Justificativa: Constatou-se que o profissional da biblioteca não se aproxima dos interagentes, tentando conhecê-lo e auxiliá-lo. Normalmente os profissionais da biblioteca estão em salas desenvolvendo trabalhos técnicos e quem realmente atende os interagentes são bolsistas/estagiários. Os profissionais da biblioteca são, na sua maior parte, responsáveis pelo processamento técnico. Só existem dois bibliotecários para atendimento ao público.

Sugestão: Incorporar no programa de gestão da biblioteca uma visão de que todos os funcionários da instituição são responsáveis por prestar auxílio aos interagentes; fornecer capacitação constante.

c) Armazenamento e conservação (Biblioteconomia).

Justificativa: Constatou-se que falta preocupação com a recuperação da informação e com seu acesso.

Sugestão: Todos os profissionais da biblioteca devem estar em constante atualização sobre os recursos informacionais, tecnológicos, novas formas de acesso e de modo mais imediato, trazer eficiência na resposta das necessidades dos interagentes.

d) Foco no acervo de livros (Biblioteconomia).

Justificativa: Os investimentos são, em sua maioria, na manutenção do acervo de livros.

Sugestão: Maior preocupação em 'ouvir' os professores, técnicos, discentes e bibliotecários sobre onde investir, quais 
materiais devem ser comprados (e quais são dispensáveis, por possuírem acesso online, por exemplo), por meio da atualização progressiva das Diretrizes que compõe a Política de Desenvolvimento de Coleções da Biblioteca, além de estudarem juntos técnicas de como gerir melhor os recursos destinados a biblioteca.

e) Responsabilidade social: cultura e educação; ênfase técnica/ferramental. (Biblioteconomia).

Justificativa: A biblioteca visa à cultura e educação, principalmente por estar em um universo educacional; não tem visão de mercado, e sua ênfase é puramente na técnica. Grande parte de suas atividades é tecnicista, enquanto que atividades culturais $\mathrm{e}$ educacionais não estão sendo exploradas de forma adequada.

Sugestão: Maior envolvimento dos profissionais da biblioteca nos recursos tecnológicos, maior aproveitamento desses recursos.

f) Conservadorismo/tradição/controle/le ntidão. (Biblioteconomia).

Justificativa: Constatou-se serviços com pouca atratividade e conservadores; poucos funcionários responsáveis no atendimento aos pedidos dos interagentes e falta de inovação nos serviços da biblioteca.

Sugestão: Investir nos programas de gerenciamento da Biblioteca, estratégias de inovação de seus serviços e buscar agilidade nos serviços.

Diante disso, tal pesquisa é apresentada como forma de elucidar a presença do paradigma da Biblioteconomia naquela instituição. Sabendo disso, a biblioteca universitária analisada poderá propor alterações necessárias na gestão institucional.

\section{CONSIDERAÇÕES FINAIS}

Vimos que a Biblioteconomia está presente em todos os serviços da biblioteca observada. "Para entender uma área, é imprescindível o conhecimento de sua gênese e da sua história, assim como das condições econômicas, sociais e culturais em que se desenvolveram". (OLIVEIRA, 2008, p. 7). Com base no que foi tratado neste artigo, uma das explicações para entendermos por que os paradigmas da Biblioteconomia aparecem mais fortemente nas academias é a questão da interdisciplinaridade.

Santos, Chacon e Veras (2015) acreditam que deveria haver maior coesão no entendimento sobre como a interdisciplinaridade vem sendo utilizada pela área de Ciência da Informação devido à velocidade que ocorrem as mudanças relacionadas à área. Segundo esses autores, acredita-se que a coesão e o entendimento são pontos de partida para uma construção de identidade da área de Ciência da Informação no Brasil. "Principalmente, ajudar a perceber como a área pode se colocar diante do campo científico e colaborar no desenvolvimento da sociedade e dos crescentes desafios a ela impostos" (SANTOS; CHACON; VERAS, 2015, p. 230).

De acordo com Ferreira (2003) há grande dificuldade em promover-se uma profissão que diante o seu conjunto possua atividades abstratas, como é o conhecimento. Embora os termos informação e CI tornaram-se institucionalizados em escolas de Biblioteconomia, trocando nomes e currículos, a questão levantada por Capurro (2007) e que fica em aberto é "o quão bem sucedidos fomos no desenvolvimento da CI como um campo saudável de investigação?".

O processo de gestão da informação nas organizações deve ser contínuo e estar sempre em aperfeiçoamento, assim como seus devidos profissionais. De acordo com Ferreira (2005), "grandes empresas estão utilizando a gestão do conhecimento para facilitar o fluxo da informação nos seus diversos setores".

"Os ambientes universitários estão associados à produção e disseminação do conhecimento, destacando-se a informação como um dos elementos relevantes nesse processo" (MAZZONI et al, 2001, p. 29). Portanto, é importante que a biblioteca esteja em constante atualização dos seus serviços e produtos, esteja aberta a mudanças, a críticas e sugestões. Além disso, o bibliotecário é fator-chave para uma biblioteca progredir, visto a importância de lidar corretamente com o fluxo da informação, fornecendo a informação certa no momento certo ao interagente com a maior agilidade possível.

Entende-se que o profissional da informação precisa estar consciente de suas aptidões, de sua capacidade de atuação, de suas habilidades comportamentais, 
sobressaltando seus pontos fortes para ocupar seu espaço no mercado competitivo. Torna-se necessária a divulgação mais efetiva da profissão e da capacidade de atuação desses profissionais nas organizações.

Além de identificar os paradigmas nesta pesquisa, busca-se apontar melhorias para a gestão da Biblioteca observada. As técnicas e os procedimentos usados por bibliotecários são ou deveriam ser baseados também em propostas teóricas da Ciência da Informação, assim como os teóricos deveriam estudar as técnicas e os procedimentos aplicados na profissão.

A maior contribuição, diante dos pontos levantados no presente estudo, foi o de conhecer a biblioteca analisada, entender onde estão os pontos fortes e fracos e sugerindo mudanças para melhoria dos seus fluxos informacionais.

\title{
PERCEPTION OF THE LIBRARY PARADIGMS PRESENCE AND INFORMATION SCIENCE IN A UNIVERSITY LIBRARY
}

\begin{abstract}
Here in, paradigmatical statements from a university library were analysed aiming to identify the presence of paradigms in Biblioteconomy and Information Sciences and point wich one of them is more representative at the institution. So far, this observation defined as object of research the main library of a university. First, brief historical reports about Biblioteconomy and Information Sciences are presented besides the instutional history. To achieve the proposed aims important data were collected in respect to acquis, material lending, as well as the number of users and collaborators. It is a qualitative, bibliographical and documental research. Last, from the paradigms of Biblioteconomy and Information Sciences exposed at current literature we could notice that the main identified paradigms at the observed library were related to biblioteconomy areas, once it is an area that is concerned to Acquis, support and technical processes.
\end{abstract}

Keywords: University library. Paradigms of Biblioteconomy. Paradigms of Information Science.

Artigo recebido em: 20/01/2017

Aceitação definitiva em:

\section{REFERÊNCIAS}

ALMEIDA, Maria Christina Barbosa de. Planejamento de bibliotecas e serviços de informação. Brasília: Briquet de Lemos, 2005. p. 37-52.

ARAÚJO, Carlos Alberto Ávila. Correntes teóricas da ciência da informação. Ci. Inf., Brasilia, v. 38, n. 3, p. 192-204, set./dez. 2009. Disponível em:

<http://www.scielo.br/pdf/ci/v38n3/v38n3a13 >. Acesso em: 10 jan. 2016.

BARBOSA, Ricardo Rodrigues et al. Novo nome e novo paradigma: da biblioteconomia à ciência da informação. Perspect. Cienc. Inf., Belo Horizonte, v. 5, n. especial, p. 81 - 91, jan./jun. 2000. Disponível em:

$<$ http://portaldeperiodicos.eci.ufmg.br/index.p $\mathrm{hp} / \mathrm{pci} /$ article/view/557/339> . Acesso em: 20 maio 2016.

BORKO, Harold. Ciência da Informação: O que é isto? Information Science: what is it? American Documentation, v. 19, n. 1, p. 35, jan. 1968. (tradução livre). Disponível em: $<$ http://www.josesales.com.br/arquivos/BOR KO\%20Harold\%20-\%20Ci\%C3\% AAncia \% 20da\%20informa\%C3\%A7\%C3\%A3o.pdf>. Acesso em: 2 maio 2016. 
CAPURRO, Rafael; HJORLAND, Birger. O conceito de informação. Perspectivas em Ciências da Informação, v. 12, n. 1, p. 148207, jan./abr. 2007. p. 148-207. Disponível em:

$<$ http://portaldeperiodicos.eci.ufmg.br/index.p hp/pci/article/view/54/47>. Acesso em: 2 jan. 2016.

CARVALHO, Eduardo Costa. A natureza social da Ciência da Informação. In: PINHEIRO, Lena Vania Ribeiro (Org.). Ciência da informação, ciências sociais e interdisciplinaridade. Brasília: Rio de Janeiro: IBICT, 1999. p. 51-60. Disponível em:

$<$ http://livroaberto.ibict.br/bitstream/1/1000/1 /PINHEIRO.\%20Ci\%C3\%AAncia\%20da\%20 Informa\%C3\%A7\%C3\%A30,\%20Ci\%C3\%A Ancias\%20Sociais\%20e\%20Interdisciplinarie dade.pdf>. Acesso em: 12 jan. 2016.

CORRÊA, Elisa C. D. Usuário, não! Interagente: proposta de um novo termo para um novo tempo. Encontros Bibli, v. 19, n. 41, p. 23-40, set./dez., 2014. Disponível em: $<$ https://periodicos.ufsc.br/index.php/eb/articl e/viewFile/15182924.2014v19n41p23/28292 >. Acesso em: 12 fev. 2016.

FERREIRA, Danielle Thiago. Profissional da informação e a gestão do conhecimento. In: SOUTO, Leonardo Fernandes (Org.). O profissional da informação em tempos de mudanças. Campinas: Alínea, 2005. p. 13 27.

. Profissional da informação: perfil de habilidades demandadas pelo mercado de trabalho. Ci. Inf., Brasília, v. 32, n. 1, p. $42-$ 49, jan./abr. 2003. Disponível em: $<$ http://www.scielo.br/scielo.php?script=sci_i ssuetoc\&pid=0100-196520030001\&l ng=en\&nrm=iso>. Acesso em: 2 maio 2016.

KUHN, Thomas S. A estrutura das revoluções científicas. São Paulo: Perspectiva, 1991.

\section{A estrutura das revoluções}

científicas. 9. ed. São Paulo: Perspectiva, 2009.
LE COADIC, Y. A Ciência da Informação.

2. ed. Brasília, DF: Briquet de Lemos, 2004.

LOUREIRO, José Mauro Matheus. Ciência da informação: nem ciência social, nem humana, apenas uma ciência diferente. In: PINHEIRO, Lena Vania Ribeiro (Org.). Ciência da informação, ciências sociais e interdisciplinaridade. Brasília: Rio de Janeiro: IBICT, 1999. p. 64-77. Disponível em:

<http://livroaberto.ibict.br/bitstream/1/1000/1 /PINHEIRO.\%20Ci\%C3\%AAncia\%20da\%20 Informa\%C3\% A7\% C3\% A3o, \%20Ci\%C3\% A Ancias\%20Sociais\%20e\%20Interdisciplinarie dade.pdf $>$. Acesso em: 12 jan. 2016.

MAZZONI, Alberto Angel et al. Aspectos que interferem na construção da acessibilidade em bibliotecas universitárias. Ci. Inf., Brasília, v. 30, n. 2, p. 29-34, maio/ago. 2001. Disponível em: <http://www.scielo.br/pdf/ci/v30n2/6209>. Acesso em: 16 maio 2016.

OLIVEIRA, Marlene de (Coord.). Ciência da informação e biblioteconomia: novos conteúdos e espaços de atuação. Belo Horizonte: UFMG, 2008. p. 7-28. PERGAMUM. Informações gerais. Disponível em:

<http://www.pergamum.pucpr.br/ redepergamum/pergamum_index.php $>$.

Acesso em: 19 maio 2016.

RUFFO, Ísis Esteves. A concepção de ciência e desenvolvimento científico após a modernidade. Disponível em:

$\langle$ http://www.ufsj.edu.br $>$. Acesso em: 21 out. 2015.

SARACEVIC, Tefko. Ciência da informação: origem, evolução e relações. Perspectivas em ciência da informação, Belo Horizonte, v. 1, n. 1, 1996. Disponível em:

<http://portaldeperiodicos.eci.ufmg.br/index.p hp/pci/article/view/235/22 >. Acesso em: 10 ago. 2014.

SANTOS, Izabel Lima dos; CHACON, Wagner; VERAS, Jefferson. Uma análise da Ciência da Informação brasileira no contexto da interdisciplinaridade. Biblionline, João Pessoa, v. 11, n. 2, p. $218-231,2015$. 
Disponível em:

<http://www.biblionline.ufpb.br/ojs2/index.p hp/biblio/article/view/26030/15183 > . Acesso em: 31 maio 2016.

SILVA, Jonathas Luiz Carvalho; FREIRE, Gustavo Henrique de Araújo. Encontros Bibli: revista eletrônica de biblioteconomia e ciência da informação, Florianópolis, v. 17, n. 33, p. 1-29, jan./abr., 2012.Disponível em: <https://periodicos.ufsc.br/index.php/eb/articl e/view/1518-2924.2012v17n33p1/21708>.

Acesso em: 1 jun. 2016.
VIEIRA, Diego de Castro; ARDIGO, Julibio David. Paradigmas da Biblioteconomia e Ciência da Informação: estudo de caso em uma unidade de informação especializada. Revista ACB, Florianópolis, v. 20, n. 1, p. 124-137, jan./abr., 2015.

VENTURA, Magda Maria. O estudo de caso como modalidade de pesquisa. Rev.

SOCERJ, Rio de Janeiro, v. 20, n. 5, p. 383386, set./out. 2007. Disponível em: <http://unisc.br/portal/upload/com_arquivo/o _estudo_de_caso_como_modalidade_de_pesq uisa.pdf>. Acesso em: 1 maio 2016. 